\title{
Pulmonary ossification and microlithiasis in a bitch with multicentric mammary tumors
}

\author{
Mahir A.G. Kubba* \\ Department of Pathology and Clinical Pathology, Faculty of Veterinary Medicine, University of Tripoli, Libya
}

\begin{abstract}
Microliths and ossification were found in the lungs of a 12-year-old bitch suffering from compound mammary gland tumor which has disseminated in the inguinal lymph node glands and the lungs. Pulmonary ossification appeared grossly as irregular stony sharp particles which infiltrated the lung tissue and were readily recognizable from under the pleura as grayish sharp protruding particles. Microscopic examination revealed the existence of intra-alveolar single or multilobular particles of ossification which are formed of lamellated osseous substance with osteocytes in lacunae. Microlith particles were also seen and were smaller, usually solitary and less frequent. They comprised strongly basophilic smooth laminated spherical particles which may enclose faintly stained substances. Both structures were not associated with inflammatory response. Larger particles appeared as white miliary spots by radiography. This article documents for a very rare case of pulmonary microlithiasis and ossification in a dog.
\end{abstract}

Keywords: Multicentric mammary tumors, Pulmonary microlithiasis, Pulmonary ossification.

\section{Introduction}

The existence of mature bone fragments and calcium concretions in the pulmonary alveoli were described in man and animals. This condition was first described in man in 1918 and was termed "pulmonary alveolar microlithiasis" in 1938 (Bush et al., 1976). In 2004, Mariotta et al. (2004) reviewed 576 cases which represented all the scientific literatures up to January 2003. In addition to others (Malhotra et al., 2010; Devi et al., 2011; Yin and Shen, 2011), they described the disease as a rare condition which occurs mostly in Europe and Asia.

The disease has familial and sporadic patterns, affects all ages and possesses no gender predilection. Pulmonary alveolar microlithiasis is even rarer in animals and the few available documents have reported it in sheep (Romboli and Del Bono, 1966), dogs (Liu et al., 1969; Brix et al., 1994; de Brot and Hilbe, 2013), a cat (Brummer et al., 1989), and few exotic animals including binturong (Bush et al., 1976), orange-utan (Kelly, 1976), Afghan pika (Madarame et al., 1989), nacht mice (Starost et al., 2002) and alpaca (Lee et al., 2012). They described the affected lungs as having grainy consistency on palpation with gritty texture on cutting. Bush et al. (1976) demonstrated a pinpoint to 2 $\mathrm{mm}$ hard whitish foci distributed throughout the lungs in binturong. Microliths appeared microscopically as circular to irregularly shaped, slightly basophilic nonbirefringent periodic acid-schiff- positive laminated concretions within alveolar walls or free in the alveoli. Mature bone concretions of variable size were also observed attached to the alveolar septa and often filled the alveolar spaces. They consisted of boney lamellae and osteocytes in lacunae arranged in concentric layers. Most investigations have ruled out associated inflammatory response. Radiographic findings have shown bilateral interstitial miliary pattern of increased pulmonary density with a 'snowstorm' or 'sandstorm' appearance (Bush et al., 1976; Brix et al., 1994). In man, these findings were often missed for miliary tuberculosis, silicosis, berylliosis, sarcoidosis, hemosiderosis, fungal infections and carcinomatosis (Malhotra et al., 2010), while deep pulmonary mycosis and lymphosarcoma were missed for in dogs (Brix et al., 1994).

In human, microliths are composed mainly of calcium phosphate (Schoenhals and Fishman, 1980; Brix et al., 1994), while those assuming boney structure possess consistency equal to bone (Bush et al., 1976). The etiology of the disease is unknown but many theories have been suggested. Possible etiologies include an inherited metabolic abnormality in the lung (Moran et al., 1997), abnormalities in calcium and phosphorus metabolism (Arslan et al., 1996), abnormalities in the immune system (Meyer et al., 1956), environmental factors (Prakash et al., 1983) and anatomic and physiologic abnormalities of the lung (Sosman et al., 1957; Moran et al., 1997). Recent investigations have identified gene SLC34A2 to be responsible (Gocmen et al., 1992; Yin and Shen, 2011). The clinical signs associated with this condition ranged from asymptomatic to respiratory insufficiency. This article documents for a very rare case of pulmonary microlithiasis and ossification in a dog. 


\section{Case Details}

A twelve years old bitch suffering from advanced multiple mammary gland tumors was euthanized because of poor prognosis. Postmortem examination revealed the involvement of three mammary glands with voluminous tumors in addition to dissemination in the inguinal lymph node glannd and the lungs. Both lungs harboured superficial and deeply seated tumor secondaries ranging from $0.5-6.0 \mathrm{~cm}$ in diameter. Both lungs were pale, not well inflated, anthracotic, with patchy emphysema. A peculiar finding was the existence of palpable foci of mineralization scattered under the pleura and deep in the parenchyma in both lungs. Those located superficially are protruding irregular grayish white stony masses of $1.0-5.0 \mathrm{~mm}$ in diameter with occasional boney spicules that perforate the pleura (Fig. 1and 2).

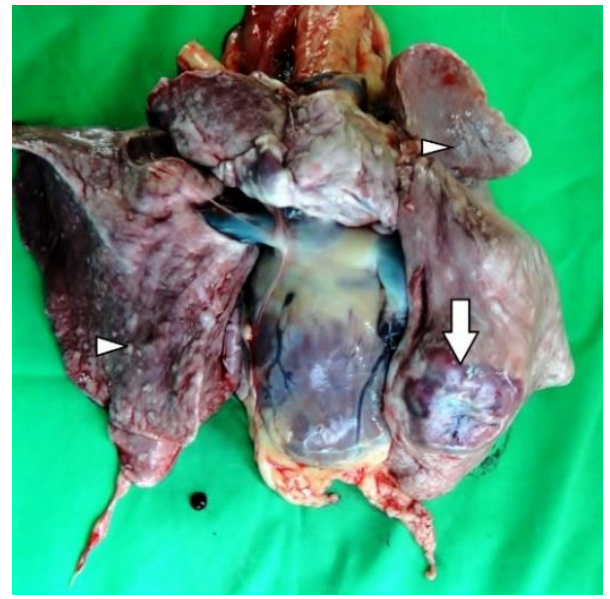

Fig. 1. Mineralization nodules are protruding from the subpleura (arrow heads). The right lung shows a large secondary tumor growth (arrow).

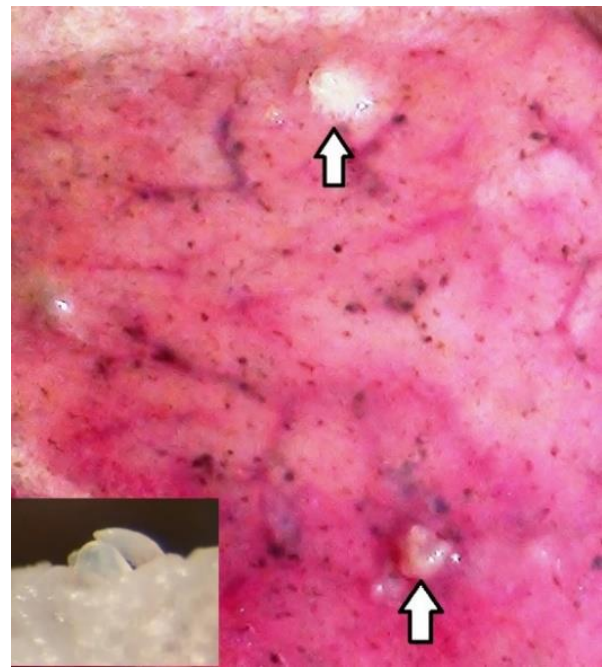

Fig. 2. Large irregular prominent white boney particles are seen through the lung surface (Arrows). Some boney spicules perforate to the lung surface through the pleura (Inset). Dark spots are Carbon particles.
The heart showed left ventricular hypertrophy and mild right ventricular dilatation. Other organs were obviously normal. Microscopic examination revealed the existence of two morphologically different tumors comprising cystic adenocarcinoma in two glands and mixed mammary tumor in the third gland. The secondary tumor growth in the inguinal glands and the lungs was that of solid adenocarcinoma. Both lungs -in addition- contained irregular single or multi-lobulated softly laminated masses of boney structure formed of osseous material and lacunated osteocytes. The outer lamellae often showed increased basophilia and numerous osteocytes while the centers had occasional areas of non-boney mineralization. Alveoli distended with such structures had their walls usually stretched or ruptured (Fig. 3 and 4).

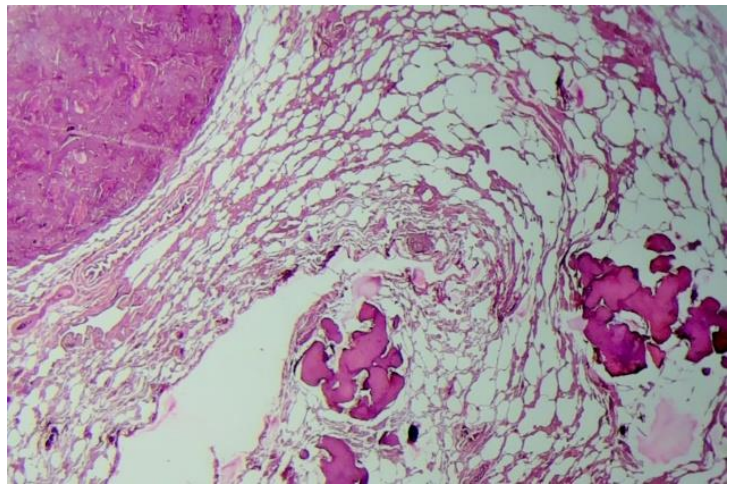

Fig. 3. Multiobular intra-alveolar mass of boney structure are seen. Part of the metastatic tumor is seen in the left upper corner. The lung is rather emphysematous (Magnification: $\mathrm{X} 40)$.

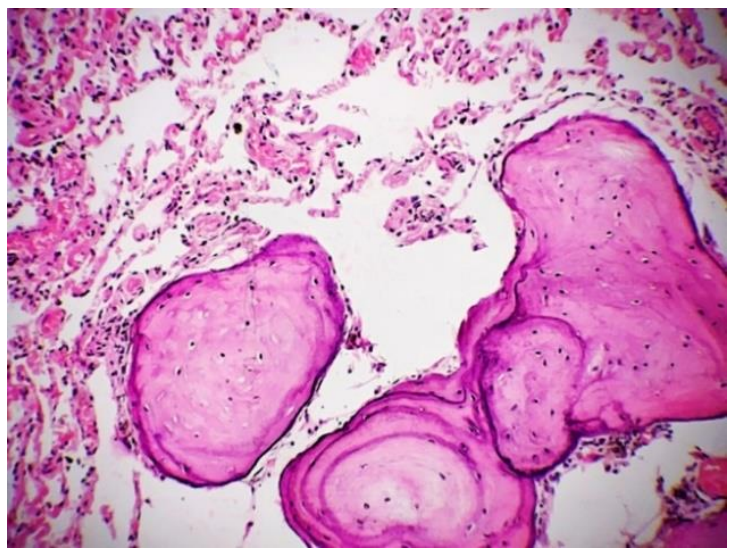

Fig. 4. Ossification lobules showing lamellated orientation with osteocytes in lacunae. They are surrounded by stretched alveolar wall membrane (Magnification: X100).

Other kind of less frequently noticed alveolar concretions has also existed. These are solitary measuring about 30 um and are formed of non- cellular deeply basophilic onion-like laminations which may enclose faint eosinophilic soft substance (Fig. 5). 


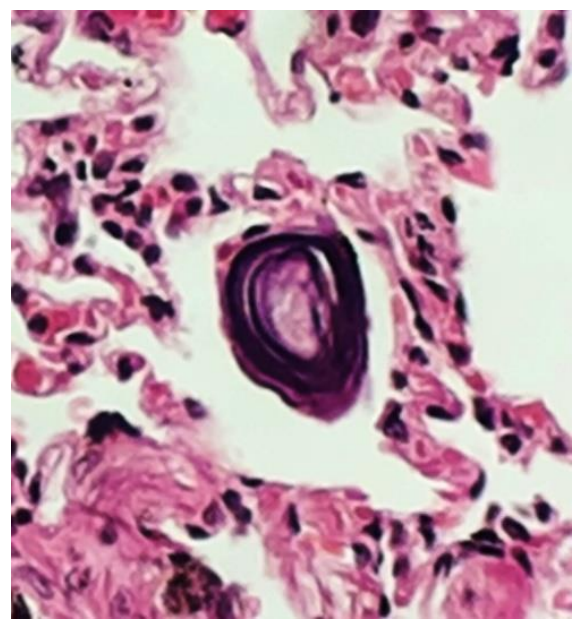

Fig. 5. Intra-alveolar onion-like concretion formed of strongly basophilic non-cellular lamination which encloses a faintly eosinophilic soft substance (Magnification: X400).

Both structures were not associated with local tissue inflammatory response. Exploration radiography has shown the ossified concretions as small whitish spots.

\section{Discussion}

Pulmonary alveolar microlithiasis is a rare pathological condition of man and animal whose etiology has not yet been resolved. Available literatures have so far reported this condition in three aged dogs of different sex, breed and diseases association. Liu et al. (1969) have reported the disease in an 11-year old Poodle with ruptured chordae tendineae of the mitral and tricuspid valves, while de Brot and Hilbe (2013) reported the disease in a 10-year-old female Bulldog with concurrent pleural mesothelioma. The third report was about a 9-year- old male English Setter dog with no history of associated disease (Brix et al., 1994).

The nature of the alveolar concretions in those reports varied from microliths in one dog (de Brot and Hilbe, 2013) to boney nodules in another (Liu et al., 1969) while the third dog possessed both kinds (Brix et al., 1994). Many investigators have suggested that microliths may provide a nidus for bone formation and the presence of few small foci of non-bony mineralization in bony tissue may confirm that concept (Bush et al., 1976; Brix et al., 1994). Both kinds of concretions existed in the current report which investigates a 12-year-old local-breed female dog with concurrent mammary gland tumor that has disseminated in the inguinal glands and the lungs. Their structure, location and lack of associated inflammatory response are in accordance with those mentioned for previous investigations. The complexity of the bony particles noticed in this dog is unique among others and the multilobular intra-alveolar morphology probably indicates an expansive pattern of growth involving adjacent alveoli.
Having reviewed the literature, this study added another case of pulmonary microlithiasis in a bitch suffering this time from mammary tumor with pulmonary dissemination. The relationship between the two conditions could neither be established nor ruled out.

\section{Conflict of interest}

The authors declare that they have no competing interests.

\section{References}

Arslan, A., Yalin, T., Akan, H. and Belet, U. 1996. Pulmonary alveolar microlithiasis associated with calcification in the seminal vesicles. J. Belge. Radiol. 97, 118-119.

Brix, A.E., Latimer, K.S., Moore, G.E. and Roberts, R.E. 1994. Pulmonary alveolar microlithiasis in a dog. Vet. Pathol. 31, 382-385.

Brummer, D.G., French, T.W. and Cline, J.M. 1989. Microlithiasis associated with chronic bronchopneumonia in a cat. J. Am. Vet. Med. Assoc. 194, 1061-1064.

Bush, M., James, A.E., Montali, R.J. and Stitik, F.P. 1976. Pulmonary alveolar microlithiasis in a binturong (Arctictis binturong): a case report. J. Am. Vet. Radiol. Soc. 17, 157-160.

de Brot, S. and Hilbe, M. 2013. Pulmonary alveolar microlithiasis with concurrent pleural mesothelioma in a dog. J. Vet. Diag. Invest. 25, 798-802.

Devi, G., Rao, H.J.M., Prathima, K.N., Das, K.M. and Jayanth, K. 2011. Pulmonary alveolar microlithiasis. Lung India 28(2), 139-141.

Gocmen, A., Toppare, M.F., Kiper, N. and Buyukpamukcu, N. 1992. Treatment of pulmonary alveolar microlithiasis with diphosphonate-preliminary results of a case. Respiration 59(4), 250-252.

Kelly, O.F. 1976. Pulmonary alveolar microlithiasis in the orange-utan (Pongo pymaeus). Acta Zool. Pathol. Antverb. 66, 53-57.

Lee, E.J., Dawood, K.E., Brudar, R. and Philbey, A.W. 2012. Pulmonary alveolar microlithiasis in an alpaca (Vicugna pacos). Aust. Vet. J. 90, 510-512.

Liu, S.K., Suter, P.F. and Ettinger, S. 1969. Pulmonary alveolar microlithiasis with ruptured chordae tendinae in mitral and tricuspid valves in a dog. J. Am. Vet. Med. Assoc. 155, 1692-1703.

Madarame, H., Kumaga, M., Suzuki, J., Watanabe, A. and Kanno, S. 1989. Pulmonary alveolar microlithiasis in Afghan pika (Ochotona rufescens rufescens). Vet. Pathol. 26, 333-337.

Malhotra, B., Sabharwal, R., Singh, M. and Singh, A. 2010. Pulmonary alveolar microlithiasis with calcified pleural plaques. Lung India 27, 250-252. 
Mariotta, S., Ricci, A., Papale, M., Clementi, F., Sposato, B., Guidi, L. and Mannino, F. 2004. Pulmonary alveolar microlithiasis: report on 576 cases published in the literature. Sarcoidosis Vasculitis and Diffuse Lung Diseases 21(3), 173181.

Meyer, N.H., Gilbert, E.S. and Kent, G. 1956. A clinical review of pulmonary microlithiasis. J. Am. Med. Assoc. 161, 1153-1157.

Moran, C.A., Hochholzer, L., Hasleton, P.S., Johnson, F.B. and Koss, M.N. 1997. Pulmonary alveolar microlithiasis. A clinicopathologic and chemical analysis of seven cases. Arch. Pathol. Lab. Med. 121, 607-611.

Prakash, U.B., Barham, S.S., Rosenow, E.C., Brown, M.L. and Payne, W.S. 1983. Pulmonary alveolar microlithiasis. A review including ultrastructural and pulmonary function studies. Mayo. Clin. Proc.
58, 290- 300.

Romboli, B. and Del Bono, G. 1966. Pneumopatia a microliti nell'ovino. Ann. Fac. Med. Vet. 19, 175201.

Schoenhals, J.A. and Fishman, A.P. 1980. Pulmonary alveolar microlithiasis. In: Pulmonary diseases and disorders, ed. Fishman AP, $1^{\text {st }}$ ed. McGraw-Hill, New York, NY, pp: 987-989.

Sosman, M.C., Dodd, G.D., Jones, W.D. and Pillmore, G.U. 1957. The familial occurrence of pulmonary alveolar microlithiasis. Am. J. Reontgenol. Radium. Ther. Nucl. Med. 77, 947-1012.

Starost, M.F., Benavides, F. and Conti, C.J. 2002. A variant of pulmonary alveolar microlithiasis in nacht mice. Vet. Pathol. 39, 390-392.

Yin, J. and Shen, K. 2011. Pulmonary alveolar microlithiasis in a child. N. Engl. J. Med. 364:e49. DOI: 10.1056/NEJMicm1002094. 